\title{
Short and long term determinants of incident multimorbidity in a cohort of 1988 earthquake survivors in Armenia
}

\author{
Anahit Demirchyan ${ }^{1 *}$, Vahe Khachadourian ${ }^{1}$, Haroutune K Armenian ${ }^{2}$ and Varduhi Petrosyan ${ }^{1}$
}

\begin{abstract}
Background: Multimorbidity, presence of two or more health conditions, is a widespread phenomenon affecting populations' health all over the world. It becomes a serious public health concern due to its negative consequences on quality of life, mortality, and cost of healthcare services utilization. Studies exploring determinants of multimorbidity are limited, particularly those looking at vulnerable populations prospectively over time. This study aimed at identifying short and long term socioeconomic, psychosocial, and health behavioral determinants of incident multimorbidity among a cohort of the 1988 Armenian earthquake survivors.

Methods: The study included a representative subsample of 725 from a larger initial cohort of the earthquake survivors. Data on this subsample were collected via four phases of this cohort study during the period 1990-2012. The final logistic regression analysis eliminated all those cases with baseline multimorbidity to investigate short and long term determinants of incident multimorbidity; this subsample included 600 participants.

Results: More than $75 \%$ of the studied sample had multimorbidity. Perceived low affordability of healthcare services, poor living standards during the post-earthquake decade, and lower education were independent predictors of incident multimorbidity developed during the period 1990-2012. Stressful life events and poor social support were among psychosocial determinants of incident multimorbidity. Participants' baseline BMI reported in 1990 was independently associated with incident multimorbidity.

Conclusions: Most of the identified determinants of incident multimorbidity in our study population were markers of social inequities, indicating that inequities pose a serious threat to both individual and public health-related outcomes. Strategies targeting to decrease such inequities along with promotion of healthy lifestyle and strengthening of social networks may considerably reduce multimorbidity among population groups with similar socioeconomic and cultural profiles.
\end{abstract}

Keywords: Multimorbidity, Determinants, Inequity, Life events, Earthquake, Cohort, Armenia

\section{Background}

Multimorbidity is a condition during which an individual suffers from co-occurrence of two or more health problems [1]. Although there are significant variations in research methodology and operational definition of the condition across studies estimating the prevalence rates of multimorbidity [2-5], the majority of findings consistently indicate that multimorbidity is a common public health

\footnotetext{
* Correspondence: ademirch@aua.am

${ }^{1}$ School of Public Health, American University of Armenia, 40 Marshal Baghramian Avenue, Yerevan 0019, Armenia

Full list of author information is available at the end of the article
}

problem [3,6-9]. Recent improvements in living standards and advancements in prevention and treatment of communicable diseases have resulted in an increase of life expectancy and consequently in a higher number and proportion of elderly population contributing to higher rates of non-communicable diseases. However, multimorbidity is not a problem limited to elderly population and could be a significant problem among those below the age of $65[6,10]$.

Multimorbidity is associated with various adverse consequences and health outcomes. Those with multimorbidity have been found to have significantly higher

\section{Biomed Central}

(c) 2013 Demirchyan et al.; licensee BioMed Central Ltd. This is an Open Access article distributed under the terms of the Creative Commons Attribution License (http://creativecommons.org/licenses/by/2.0), which permits unrestricted use, distribution, and reproduction in any medium, provided the original work is properly cited. 
rates of health services utilization and eventually higher medical expenditure than those without $[8,11]$. Negative impacts of multimorbidity on the quality of life and functioning have been well established in the literature [9,12-15]. Multimorbidity is also associated with poorer self reported health [16]. Researchers have also found that those with multimorbidity have higher rates of mortality $[9,17,18]$.

Several studies have focused on exploring risk factors and determinants of multimorbidity [6,19-22] and suggested that the risk of multimorbidity increases with age. Inequities are also associated with multimorbidity [23]. Socioeconomic status is consistently found to be an important determinant of multimorbidity $[6,19,20,24]$. Insufficient nutrition and food intake are significantly associated with higher risks of multimorbidity [25] highlighting the relation between inequities and multimorbidity. Additionally, obesity is also found to be associated with multimorbidity [19].

A majority of studies examining the relation between education and multimorbidity indicated that lower education is an independent determinant of multimorbidity $[21,22,26]$. Very few studies have also explored the psychosocial determinants of multimorbidity: low levels of social support and living alone were among the factors contributing to multimorbidity [19,27].

Despite the high rates and burden of multimorbidity, recent review papers noted that only a limited number of studies aimed at exploring determinants and risk factors of multimorbidity $[9,15]$. To better deal with consequences of such an adverse phenomenon, a better understanding of the risk factors for multimorbidity among diverse study populations becomes essential.

In December 1988 an earthquake with a magnitude of 6.9 on the Richter scale struck the northern part of Armenia, damaging one-third of the countries' territory and making more than 500,000 people homeless. The number of those injured exceeded 100,000 and over 25,000 died. Shortly after the earthquake, in early 1990's, the very difficult socio-economic transition from Soviet to independent Armenia further affected populations' living standards. In 1990, a large representative sample of earthquake survivors from the biggest cities in the north of Armenia was involved in a longitudinal study of physical and mental health outcomes [28]. A subsample of this cohort was followed for 22 years, providing a unique opportunity to investigate the long-term effects of certain baseline characteristics of the survivors on their current health outcomes. The purpose of this study was to examine the role of survivors' selected baseline and current characteristics on newly occurring multimorbidity during 1990-2012. Those characteristics were grouped in socioeconomic, health behavior, and psychosocial dimensions.

\section{Methods}

\section{Participants}

The study participants were a sample of 725 individuals from a cohort of the 1988 earthquake survivors. The initial cohort consisted of all employees of the healthcare services in the earthquake zone and their family members - 32,743 individuals, who participated in a baseline assessment in 1990. A year later, a psychopathological investigation was carried out among 1,785 individuals of this cohort selected through geographically stratified random sampling to achieve higher representation from areas most affected by the earthquake $[29,30]$. Eighty percent of this study group was followed in 2012 and 725 individuals participated in a complete follow-up assessment. Of these, 124 had multimorbidity at baseline and were eliminated from the final analysis to explore the determinants of incident multimorbidity. The studied sample was representative for the population of the earthquake area aged 40 and over in terms of its major characteristics [31]. The baseline assessments collected detailed data on respondents' earthquake-related experiences and outcomes, self-reported physical and mental health status, health behavior, access to healthcare services, and socio-demographic characteristics. The 2012 assessment collected data on respondents' self-reported physical and mental health status, health behavior, access to healthcare services, and socio-demographic characteristics more than two decades after the baseline assessments. The Institutional Review Board of the American University of Armenia reviewed and approved the protocol for the current study.

\section{Variables}

The outcome variable, incident multimorbidity, was based on the number of respondent's self-reported non-communicable health conditions at the current assessment. Respondents were provided with a predetermined list of conditions (including both physical and mental conditions) and the option "other" to make the listing of conditions comprehensive. This variable was dichotomized into two or more diseases versus one or no disease.

The independent variables reflected characteristics collected at two time points - in 1990s and in 2012 follow-up survey, and were grouped into three dimensions: socioeconomic, health behavior, and psychosocial. The socioeconomic dimension included age, gender, education, employment, marital status, living alone, perceived low affordability of healthcare services, socio-economic status (SES) score (ranging from 0 to 24), and perceived living standards before the earthquake and during the first decade after the earthquake. The dimension of health behavior included smoking, drinking alcohol once a week or more, binge drinking, uncontrolled use of salt, body mass index (BMI), regular participation in 
sport and walking three hours per week or more. The psychosocial dimension included earthquake-caused material loss score (ranging from 0 to 8 ), earthquake-related deaths in the family, earthquake-related injuries, posttraumatic growth score (ranging from 0 to 20), dignity score (ranging from 18 to 90), number of stressful life events, memory score as an indicator of cognitive functioning (ranging from 0 to 8 ), and social support. Some of these variables were available either from the baseline or current assessments, some - from both assessments (Table 1).

Age, BMI, number of stressful life events and all the score variables were treated as continuous variables in logistic regression analysis after checking their linearity on logistic scale. The remaining variables were dichotomized. All the dichotomized variables were single-item variables, except social support. This variable was based on a cumulative score generated from the responses to seven social support items and then dichotomized at a threshold corresponding to its median as this score demonstrated parabolic pattern on the logistic scale.

\section{Analysis}

The main characteristics of the sample were investigated through descriptive analysis and compared between no/ single morbidity and incident multimorbidity groups using Chi-square test for proportions and $t$-test for means. This was followed by bivariate logistic regression analysis to identify the variables significantly associated with incident multimorbidity. The variables found significant in the bivariate analysis at the $\mathrm{p}<0.25$ level [32] were entered into multivariate analysis in different combinations to check their controlled/mediated effect on the outcome. The cases with baseline multimorbidity were eliminated from the logistic regression analysis to identify factors associated with incident cases of multimorbidity. The research team assessed the fit of the final model of independent long and short term determinants of incident multimorbidity using Hosmer-Lemeshow goodness-of-fit test and the area under the Receiver Operating Characteristic (ROC) curve.

The research team also calculated the adjusted relative risks for those determinants of incident multimorbidity, information on which was collected progressively [33]. The method of generalized linear regression with a log link, normal distribution, and robust variance estimator was used for adjusted relative risk estimation [34]. The analysis was conducted using SPSS-18 and STATA-10 statistical software. Missing values comprised $3.8 \%$ of cases included in logistic regression analysis and were treated as missing during the analysis.

\section{Results}

The mean age of participants was 58.4 (SD 12.0) ranging from 39 to 90 . Over two-third of them were women.
The majority (69.1\%) of the sample had secondary education and less than half (44.9\%) were employed. The reported prevalence of multimorbidity in the total sample was $76.7 \%$. In the older age group (65 years old and more) this rate was $86.7 \%$ while in the younger age group (39-64 years old) it was $72.5 \%$. Among those with multimorbidity, hypertension and arthritis were the most commonly reported conditions $(63.8 \%$ and $62.9 \%$, respectively).

Table 1 provides the distribution of the selected baseline and current variables grouped in socioeconomic, health behavioral and psychosocial dimensions between those with baseline multimorbidity, incident multimorbidity and without multimorbidity. The group with incident multimorbidity was significantly older and less educated than the group without multimorbidity. Those with incident multimorbidity reported significantly lower employment rate and socio-economic status score, poorer perceived living standards during the first ten years following the earthquake, and lower affordability of healthcare services.

This group spent significantly less time on walking than those without multimorbidity. The information on health-related behavioral characteristics collected 22 years ago revealed statistically significant differences in body mass index (higher in the multimorbidity group) and the rates of regular participation in sport (lower in the multimorbidity group).

Variables from the baseline assessment related to the direct exposure to earthquake - earthquake-caused injuries, deaths among family members, and material loss, did not differ significantly between the groups with incident multimorbidity and without multimorbidity (Table 1 ). However, the life-time exposure to stress measured by the number of experienced stressful life events was significantly higher in the incident multimorbidity group. This group reported less social support and had lower memory and dignity scores compared to those without multimorbidity.

The findings of the bivariate logistic regression analysis confirmed the above-mentioned associations. The final multivariate logistic regression model identified six independent short and long term determinants of incident multimorbidity (Table 2). The number of stressful life events (both negative and positive) was strongly associated with multimorbidity. Each additional stressful event experienced by a respondent was associated with 15\% higher chance of incident multimorbidity. This variable mediated the effect of age on multimorbidity, making age insignificant in the final model. Unlike current SES score, perceived living standards during the first ten years following the earthquake were also strongly related to incident multimorbidity in the final model. Rating family's living standards as poor during the 
Table 1 Distribution of selected baseline and current variables between groups with and without multimorbidity among a cohort of the 1988 Armenian earthquake survivors

\begin{tabular}{|c|c|c|c|c|c|c|}
\hline & \multirow[t]{2}{*}{$\mathrm{n}$} & \multirow{2}{*}{$\begin{array}{l}\text { Baseline } \\
\text { multi-morbidity } \\
(\mathrm{N}=124)\end{array}$} & \multicolumn{3}{|c|}{ Incident multimorbidity } & \multirow[t]{2}{*}{ Total $(\mathrm{N}=721)$} \\
\hline & & & No $(N=157)$ & Yes $(\mathrm{N}=440)$ & P value & \\
\hline \multicolumn{7}{|l|}{ Socioeconomic variables: } \\
\hline Current age, mean (SD) & 721 & $64.5(10.4)$ & $53.6(10.5)$ & $58.4(12.1)$ & 0.000 & $58.4(12.0)$ \\
\hline Current socio-economic status score, mean (SD) & 713 & $12.0(3.8)$ & $13.3(4.2)$ & $12.0(3.9)$ & 0.000 & $12.3(4.0)$ \\
\hline \multicolumn{7}{|l|}{ Gender: } \\
\hline Female, \% & 721 & 81.5 & 62.4 & 66.4 & 0.381 & 68.1 \\
\hline Male, \% & & 18.5 & 37.6 & 33.6 & & 31.9 \\
\hline \multicolumn{7}{|l|}{ Current education: } \\
\hline Secondary/lower, \% & 721 & 83.1 & 61.6 & 80.0 & 0.000 & 69.1 \\
\hline University/higher, \% & & 16.9 & 38.9 & 20.0 & & 23.6 \\
\hline \multicolumn{7}{|l|}{ Current employment: } \\
\hline Employed, \% & 721 & 41.1 & 58.6 & 41.1 & 0.000 & 44.9 \\
\hline Unemployed, \% & & 58.9 & 41.4 & 58.9 & & 55.1 \\
\hline \multicolumn{7}{|l|}{ Current marital status: } \\
\hline Married, \% & 721 & 58.9 & 72.6 & 72.3 & 1.000 & 70.0 \\
\hline Single/divorced/widowed, \% & & 41.1 & 27.4 & 27.7 & & 30.0 \\
\hline Currently living alone, \% & 720 & 9.8 & 7.0 & 6.1 & 0.705 & 6.9 \\
\hline Current low affordability of healthcare, $\%$ & 720 & 61.3 & 35.7 & 64.9 & 0.000 & 57.9 \\
\hline \multicolumn{7}{|l|}{ Living standards during post-earthquake decade: } \\
\hline Very good/good/average, \% & 717 & 45.5 & 67.5 & 48.3 & 0.000 & 52.0 \\
\hline Poor/very poor, \% & & 54.5 & 32.5 & 51.7 & & 48.0 \\
\hline \multicolumn{7}{|l|}{ Baseline living standards: } \\
\hline Good/average, \% & 716 & 60.5 & 72.7 & 73.1 & 1.000 & 70.8 \\
\hline Poor/very poor, \% & & 39.5 & 27.3 & 26.9 & & 29.2 \\
\hline \multicolumn{7}{|l|}{ Health behavioral variables: } \\
\hline Current smoking, \% & 721 & 5.6 & 24.2 & 20.0 & 0.305 & 18.4 \\
\hline Current drinking once a week or more, $\%$ & 716 & 4.9 & 16.0 & 10.3 & 0.061 & 10.6 \\
\hline Current binge drinking, $\%$ & 713 & 4.9 & 8.4 & 7.6 & 0.728 & 7.3 \\
\hline Current regular walking ( $\geq 3$ hours/week), \% & 716 & 33.3 & 45.9 & 36.0 & 0.035 & 37.7 \\
\hline Current uncontrolled use of salt, \% & 716 & 22.1 & 26.1 & 31.1 & 0.264 & 28.5 \\
\hline Baseline smoking, \% & 721 & 8.9 & 24.8 & 20.2 & 0.257 & 19.3 \\
\hline Baseline drinking (perceived), \% & 721 & 29.0 & 23.6 & 25.5 & 0.669 & 25.7 \\
\hline Baseline regular participation in sport, $\%$ & 716 & 2.4 & 9.0 & 4.3 & 0.041 & 5.0 \\
\hline Baseline body mass index, mean (SD) & 713 & $26.2(4.4)$ & $24.2(3.9)$ & $25.5(4.6)$ & 0.002 & $25.3(4.5)$ \\
\hline \multicolumn{7}{|l|}{ Psychosocial variables: } \\
\hline Current good social support, \% & 706 & 49.2 & 77.9 & 54.7 & 0.000 & 58.8 \\
\hline Current post-traumatic growth score, mean (SD) & 694 & $9.8(5.0)$ & $10.3(5.0)$ & $9.6(5.2)$ & 0.144 & $9.8(5.1)$ \\
\hline Current dignity score, mean (SD) & 698 & $70.8(7.7)$ & $71.6(6.9)$ & $70.1(6.9)$ & 0.018 & $70.6(7.1)$ \\
\hline Current memory score, mean (SD) & 719 & $4.6(2.2)$ & $5.4(2.1)$ & $4.7(2.2)$ & 0.001 & $4.8(2.2)$ \\
\hline Number of stressful life events, mean (SD) & 721 & $9.4(2.7)$ & $7.5(2.6)$ & $8.7(2.7)$ & 0.000 & $8.6(2.7)$ \\
\hline
\end{tabular}


Table 1 Distribution of selected baseline and current variables between groups with and without multimorbidity among a cohort of the 1988 Armenian earthquake survivors (Continued)

\begin{tabular}{lllllll}
\hline Earthquake-caused material loss score, mean (SD) & 716 & $3.0(1.9)$ & $2.5(2.0)$ & $2.6(2.0)$ & 0.589 & $2.7(2.0)$ \\
Earthquake-related deaths in the family, \% & 721 & 10.5 & 7.6 & 9.8 & 0.521 & 9.4 \\
Earthquake-related injuries, \% & 721 & 16.9 & 7.6 & 6.6 & 0.713 & 8.6 \\
\hline
\end{tabular}

$N$ number of respondents in each group, $n$ number of valid responses, SD Standard deviation. $P$ value two-sided.

post-earthquake decade was related to $68 \%$ higher chance of incident multimorbidity.

Three variables reflecting the current situation remained in the final model - perceived affordability of healthcare, social support, and education (Table 2). Perceived low affordability of healthcare was associated with 2.36 times higher chance of reporting incident multimorbidity. Good social support reduced the chance of incident multimorbidity over two times. University or higher education was associated with $44 \%$ lower chance of incident multimorbidity.

Of the behavioral variables obtained over two decades ago, BMI remained in the final model of predictors of incident multimorbidity. When controlling for all other significant variables, each one-point increase in BMI increased by $6 \%$ the chance of developing multimorbidity over this 22-year period. The final model achieved good fit indices - the p-value of 0.803 for Hosmer \& Lemeshow goodness of fit test and the area of 0.752 under the ROC curve (Table 2).

Using the advantage the cohort study design provides, we calculated adjusted relative risks for the variables reflecting baseline characteristics of the participants BMI at baseline, perceived living standards during the post-earthquake decade, and the number of stressful life events (Table 3). The findings were consistent with the results of multivariate logistic regression analysis - all three variables remained significant predictors of incident

Table 2 Logistic regression model on predictors of incident multimorbidity among a cohort of the 1988 Armenian earthquake survivors $(\mathrm{N}=600$, valid $\mathrm{N}=577$ )

\begin{tabular}{|c|c|c|c|}
\hline Characteristics & OR & $95 \% \mathrm{Cl}$ & $P$ value \\
\hline Current good social support & 0.44 & $0.28-0.70$ & 0.000 \\
\hline Number of stressful life events & 1.15 & $1.07-1.25$ & 0.000 \\
\hline Current low affordability of healthcare & 2.36 & $1.56-3.58$ & 0.000 \\
\hline Current university/higher education & 0.56 & $0.36-0.87$ & 0.010 \\
\hline $\begin{array}{l}\text { Perceived poor living standards } \\
\text { during post-earthquake } 10 \text { years }\end{array}$ & 1.68 & $1.10-2.57$ & 0.017 \\
\hline Baseline body mass index & 1.06 & $1.01-1.11$ & 0.026 \\
\hline Model's fit statistics: & \multicolumn{3}{|c|}{$\begin{array}{r}\text { Hosmer \& Lemeshow goodness } \\
\text { of fit test, } p=0.803\end{array}$} \\
\hline & \multicolumn{3}{|c|}{ Area under the ROC curve $=0.752$} \\
\hline
\end{tabular}

$N$ number of cases.

$O R$ odds ratio.

$\mathrm{Cl}$ confidence interval. multimorbidity. When controlling for all other significant variables, the risk of developing multimorbidity was $12 \%$ higher for those with perceived poor living standards during the post-earthquake decade as compared to those with perceived average/good living standards during that period. On average, the risk of developing multimorbidity increased independently by $1 \%$ for each additional unit of the baseline BMI $(\mathrm{kg} / \mathrm{m} 2)$ and by $3 \%$ for each additional stressful life event over a respondent's lifetime.

\section{Discussion}

This study investigated the determinants of incident multimorbidity in the cohort of the 1988 Armenian earthquake survivors. The study design provided a unique opportunity to identify short and long term determinants of incident multimorbidity in this disadvantaged population group. Indeed, the information on some long term determinants of incident multimorbidity developed during the period 1990-2012 was collected prospectively. The six independent predictors of incident multimorbidity identified through this study included both current characteristics (social support, affordability of healthcare) and previous experiences reported retrospectively (number of stressful life events and poor living standards during the first post-earthquake decade) or prospectively in 1990 (BMI). Almost all these determinants were markers of social inequities or were closely related to inequities.

The prevalence of multimorbidity in our sample (76.7\%) was closer to the higher end of estimates reported by other studies among similar age groups [7,26,35,36]. We believe that the high prevalence observed in this study could

\begin{tabular}{|c|c|c|c|}
\hline Characteristics & $\mathrm{RR}^{* *}$ & $95 \% \mathrm{Cl}$ & $P$ value \\
\hline Baseline body mass index & 1.01 & $1.00-1.02$ & 0.006 \\
\hline $\begin{array}{l}\text { Perceived poor living standards } \\
\text { during post-earthquake } 10 \text { years }\end{array}$ & 1.12 & $1.03-1.22$ & 0.008 \\
\hline Number of stressful life events & 1.03 & $1.02-1.04$ & 0.000 \\
\hline \multicolumn{4}{|c|}{$\begin{array}{l}N \text { number of cases. } \\
C l \text { confidence interval. } \\
{ }^{*} \text { Generalized linear model, with a log link, normal distribution, and robust } \\
\text { variance estimator. } \\
{ }^{*} R R \text { relative risk, adjusted also for current low affordability of healthcare, } \\
\text { current good social support, and current education. }\end{array}$} \\
\hline
\end{tabular}

Table 3 Computed relative risks of developing incident multimorbidity for those with selected baseline characteristics among a cohort of the 1988 Armenian earthquake survivors (valid $\mathbf{N}=\mathbf{5 7 7}$ )

*Generalized linear model, with a log link, normal distribution, and robust

current good social support, and current education. 
be attributable to continuous stress exposure of this population exacerbated by extremely high rates of poverty (more than $45 \%$ of the population) in the earthquake zone [37].

Although the majority of multimorbidity studies found that older age is associated with a higher risk of multimorbidity $[3,6,19,21]$, the strong significant relationship between age and multimorbidity in our sample was largely mediated by the number of stressful life events, suggesting that experiencing stressful events during the lifespan might be a more important factor for incident multimorbidity than the lifespan itself. However, the stressful life events that our participants have lived through were more severe than that usually observed in the general population. Various studies have examined the role of stressful life events on morbidity, and the adverse effect of such events on mental and physical health is well established in the literature [38-40]. Nonetheless, we identified only one study that has examined the relation between life events and multimorbidity and found no independent association [41]. To our knowledge, the current study was the first to find that the number of stressful life events was associated with higher risk of multimorbidity.

The majority of studies investigating the association between BMI and multimorbidity were cross-sectional [19,41]; this study explored the long-term association between baseline BMI and incident multimorbidity. Lack of BMI measures from 2012 limited us in investigating the association between incident multimorbidity and different scenarios of changes in BMI over time. Nonetheless, this study suggests that BMI is an independent long-term predictor of incident multimorbidity with higher BMI values contributing to multimorbidity two decades later - a finding that deserves attention and further investigation.

Studies have reported that lower education is associated with higher rates of multimorbidity $[3,21,26]$. Our findings are consistent with this indicating less multimorbidity in those with higher education. Education is a wellestablished marker of social inequities in health. Its effect on multimorbidity might be due to both higher socio-economic status and healthier behaviors of individuals with higher education compared to those with lower education [42].

The positive impact of social support on health is highlighted in various studies. The significant association between concurrent social support and multimorbidity in our sample was also in line with Van den Akker et. al findings on the association of social network and multimorbidity [27]. Although the cross-sectional nature of the data on this variable does not provide the opportunity to check the direction of such association, it still indicates the beneficial effect of well-developed social networks on population's health status.
Material conditions are among factors explaining the major role of social inequities in health [43] and multimorbidity [19,44]. In our sample those reporting lower living standards during the 10 years following the earthquake (1989-1999) had higher odds of suffering from multimorbidity in 2012. Interestingly, the current socioeconomic status score was not associated with incident multimorbidity in the final model. This association was largely mediated by the perceived living standards during the decade following the earthquake, suggesting an existing lag time between poor socioeconomic conditions and their impact on multimorbidity outcome.

In agreement with the identified adverse relation between socio-economic status and multimorbidity, we revealed that those reporting poor affordability of health care were at higher risk of having incident multimorbidity. This finding is consistent with an earlier study in Armenia, which identified low affordability of healthcare to be an independent predictor of self-rated poor health among women [45]. When we consider the higher need for utilizing health care services among those suffering from multiple health conditions, the low affordability of these services among them becomes an urgent and essential issue to address.

There were a number of limitations in the current study. The data we used were all self-reported, which can be subject to reporting bias. Some of our data were cross-sectional limiting us to draw conclusions on the direction of the causality of the associations. Our study population was a cohort of earthquake survivors who lived in extremely difficult conditions during the last two decades. Therefore, caution is needed when generalizing the findings of this study among other populations.

As the majority of the independent determinants of incident multimorbidity identified through this study were related to social inequities, developing and implementing strategies targeting social inequities would be important for this population as well as for other disadvantaged population groups in other countries. This study also highlights the importance of promotion of healthy lifestyle and weight control starting from younger ages. Building well-functioning social networks could further reduce multimorbidity in the areas affected by natural and man-made disasters. The findings of this study could be applicable for improving health outcomes in other countries with social, economic and wealth distribution profiles comparable to that in Armenia.

Competing interests

VP is an associate editor (unpaid) at the International Journal for Equity in Health.

Authors' contributions

All authors participated in conceptualizing the study and designing the survey. AD performed the analysis, $A D$ and VK drafted the manuscript. HA 
and VP substantially contributed to the interpretation of data and critically revised the manuscript. All authors read and approved the final manuscript.

\section{Acknowledgements}

The first three phases of the study were supported by a grant from the Armenian Relief Society, Inc., Watertown, MA 012172 USA and by the Ministry of Health of the Republic of Armenia. The Turpanjian Family Educational Foundation financed the recent $4^{\text {th }}$ phase of this study.

\section{Author details}

${ }^{1}$ School of Public Health, American University of Armenia, 40 Marshal Baghramian Avenue, Yerevan 0019, Armenia. ${ }^{2}$ Department of Epidemiology, Fielding School of Public Health, UCLA, Los Angeles, CA, USA.

Received: 19 March 2013 Accepted: 23 May 2013

Published: 20 August 2013

\section{References}

1. van den Akker M, Buntinx F, Knottnerus JA: Comorbidity or multimorbidity; what's in a name? A review of the literature. Eur J Gen Pract 1996, 2:65-70.

2. Fortin M, Stewart M, Poitras ME, Almirall J, Maddocks H: A systematic review of prevalence studies on multimorbidity: toward a more uniform methodology. Ann Fam Med 2012, 10:142-151.

3. van den Akker M, Buntinx F, Metsemakers JF, Roos S, Knottnerus JA: Multimorbidity in general practice: prevalence, incidence, and determinants of co-occurring chronic and recurrent diseases. J Clin Epidemiol 1998, 51:367-375.

4. van den Akker M, Buntinx F, Roos S, Knottnerus JA: Problems in determining occurrence rates of multimorbidity. J Clin Epidemiol 2001, 54:675-679.

5. Diederichs C, Berger K, Bartels DB: The measurement of multiple chronic diseases-a systematic review on existing multimorbidity indices. J Gerontol A Biol Sci Med Sci 2011, 66:301-311.

6. Barnett K, Mercer SW, Norbury M, Watt G, Wyke S, Guthrie B: Epidemiology of multimorbidity and implications for health care, research, and medical education: a cross-sectional study. Lancet 2012, 380:37-43.

7. Fortin M, Bravo G, Hudon C, Vanasse A, Lapointe L: Prevalence of multimorbidity among adults seen in family practice. Ann Fam Med 2005, 3:223-228.

8. Wolff JL, Starfield B, Anderson G: Prevalence, expenditures, and complications of multiple chronic conditions in the elderly. Arch Intern Med 2002, 162:2269-2276.

9. Salive ME: Multimorbidity in older adults. Epidemiol Rev 2013, 35:75-83.

10. Taylor AW, Price K, Gill TK, Adams R, Pilkington R, Carrangis N, Shi Z, Wilson D: Multimorbidity - not just an older person's issue. Results from an Australian biomedical study. BMC Public Health 2010, 10:718.

11. Rochon PA, Katz JN, Morrow LA, McGlinchey-Berroth R, Ahlquist MM, Sarkarati $M$, Minaker KL: Comorbid illness is associated with survival and length of hospital stay in patients with chronic disability. A prospective comparison of three comorbidity indices. Med Care 1996, 34:1093-1101

12. Kim KI, Lee JH, Kim CH: Impaired health-related quality of life in elderly women is associated with multimorbidity: results from the korean national health and nutrition examination survey. Gend Med 2012, 9:309-318.

13. Fortin M, Lapointe L, Hudon C, Vanasse A, Ntetu AL, Maltais D: Multimorbidity and quality of life in primary care: a systematic review. Health Qual Life Outcomes 2004, 2:51.

14. Fortin M, Bravo G, Hudon C, Lapointe L, Almirall J, Dubois MF, Vanasse A: Relationship between multimorbidity and health-related quality of life of patients in primary care. Qual Life Res 2006, 15:83-91.

15. Marengoni A, Angleman S, Melis R, Mangialasche F, Karp A, Garmen A, Meinow B, Fratiglioni L: Aging with multimorbidity: a systematic review of the literature. Ageing Res Rev 2011, 10:430-439.

16. Perruccio AV, Katz JN, Losina E: Health burden in chronic disease: multimorbidity is associated with self-rated health more than medical comorbidity alone. J Clin Epidemiol 2012, 65:100-106.

17. Gijsen R, Hoeymans N, Schellevis FG, Ruwaard D, Satariano WA, van den Bos GA: Causes and consequences of comorbidity: a review. J Clin Epidemiol 2001, 54:661-674.
18. Poses RM, McClish DK, Smith WR, Bekes C, Scott WE: Prediction of survival of critically ill patients by admission comorbidity. J Clin Epidemiol 1996, 49:743-747.

19. Walker AE: Multiple chronic diseases and quality of life: patterns emerging from a large national sample, Australia. Chronic IIIn 2007, 3:202-218.

20. Uijen AA, van de Lisdonk EH: Multimorbidity in primary care: prevalence and trend over the last 20 years. Eur J Gen Pract 2008, 14(Suppl 1):28-32.

21. Marengoni A, Winblad B, Karp A, Fratiglioni L: Prevalence of chronic diseases and multimorbidity among the elderly population in Sweden. Am J Public Health 2008, 98:1198-1200.

22. Schafer I, Hansen H, Schon G, Hofels S, Altiner A, Dahlhaus A, Gensichen J, Riedel-Heller $S$, Weyerer $S$, Blank WA, et al: The influence of age, gender and socio-economic status on multimorbidity patterns in primary care. First results from the multicare cohort study. BMC Health Serv Res 2012, 12:89.

23. Starfield B: The hidden inequity in health care. Int J Equity Health 2011, 10:15.

24. Agborsangaya CB, Lau D, Lahtinen M, Cooke T, Johnson JA: Multimorbidity prevalence and patterns across socioeconomic determinants: a cross-sectional survey. BMC Public Health 2012, 12:201.

25. Sharkey JR: Risk and presence of food insufficiency are associated with low nutrient intakes and multimorbidity among homebound older women who receive home-delivered meals. J Nutr 2003, 133:3485-3491.

26. Nagel G, Peter R, Braig S, Hermann S, Rohrmann S, Linseisen J: The impact of education on risk factors and the occurrence of multimorbidity in the EPIC-Heidelberg cohort. BMC Public Health 2008, 8:384.

27. van den Akker M, Buntinx F, Metsemakers JF, van der Aa M, Knottnerus JA: Psychosocial patient characteristics and GP-registered chronic morbidity: a prospective study. J Psychosom Res 2001, 50:95-102.

28. Armenian HK, Melkonian A, Noji EK, Hovanesian AP: Deaths and injuries due to the earthquake in Armenia: a cohort approach. Int J Epidemiol 1997, 26:806-813.

29. Armenian HK, Morikawa M, Melkonian AK, Hovanesian AP, Haroutunian N, Saigh PA, Akiskal K, Akiskal HS: Loss as a determinant of PTSD in a cohort of adult survivors of the 1988 earthquake in Armenia: implications for policy. Acta Psychiatr Scand 2000, 102:58-64.

30. Armenian HK, Morikawa M, Melkonian AK, Hovanesian A, Akiskal K, Akiskal HS: Risk factors for depression in the survivors of the 1988 earthquake in Armenia. J Urban Health 2002, 79:373-382.

31. National Statistical Service of the Republic of Armenia: The Results of Census of Republic of Armenia of 2001. Yerevan: National Statistical Service of the Republic of Armenia; 2003.

32. Hosmer DW, Lemeshow S: Applied logistic regression. 2nd edition. New York: A Wiley-Interscience Publication; 2000.

33. Diaz-Quijano FA: A simple method for estimating relative risk using logistic regression. BMC Med Res Methodol 2012, 12:14.

34. Cummings P: Methods for estimating adjusted risk ratios. SJ 2009, 9:175-196.

35. Schram MT, Frijters D, van de Lisdonk EH, Ploemacher J, de Craen AJ, de Waal MW, van Rooij FJ, Heeringa J, Hofman A, Deeg DJ, Schellevis FG: Setting and registry characteristics affect the prevalence and nature of multimorbidity in the elderly. J Clin Epidemiol 2008, 61:1104-1112.

36. John R, Kerby DS, Hennessy CH: Patterns and impact of comorbidity and multimorbidity among community-resident American Indian elders. Gerontologist 2003, 43:649-660.

37. National Statistical Service of the Republic of Armenia: Social snapshot and poverty in Armenia. In Book social snapshot and poverty in Armenia. Yerevan: National Statistical Service of the Republic of Armenia; 2012.

38. Brown GW: Life events and affective disorder: replications and limitations. Psychosom Med 1993, 55:248-259.

39. Kessler RC: The effects of stressful life events on depression. Annu Rev Psychol 1997, 48:191-214

40. Tosevski DL, Milovancevic MP: Stressful life events and physical health. Curr Opin Psychiatry 2006, 19:184-189.

41. van den Akker M, Buntinx F, Metsemakers JF, Knottnerus JA: Marginal impact of psychosocial factors on multimorbidity: results of an explorative nested case-control study. Soc Sci Med 2000, 50:1679-1693.

42. Diderichsen F, Andersen I, Manuel C, Andersen AM, Bach E, Baadsgaard M, Bronnum-Hansen H, Hansen FK, Jeune B, Jorgensen T, Sogaard J: Health inequality-determinants and policies. Scand J Public Health 2012, 40:12-105. 
43. Di Cesare M, Khang YH, Asaria P, Blakely T, Cowan MJ, Farzadfar F, Guerrero R, Ikeda N, Kyobutungi C, Msyamboza KP, et al: Inequalities in non-communicable diseases and effective responses. Lancet 2013, 381:585-597.

44. Salisbury C, Johnson L, Purdy S, Valderas JM, Montgomery AA: Epidemiology and impact of multimorbidity in primary care: a retrospective cohort study. Br J Gen Pract 2011, 61:e12-21.

45. Demirchyan A, Petrosyan V, Thompson ME: Gender differences in predictors of self-rated health in Armenia: a population-based study of an economy in transition. Int J Equity Health 2012, 11:67.

doi:10.1186/1475-9276-12-68

Cite this article as: Demirchyan et al:: Short and long term determinants of incident multimorbidity in a cohort of 1988 earthquake survivors in Armenia. International Journal for Equity in Health 2013 12:68.

\section{Submit your next manuscript to BioMed Central and take full advantage of:}

- Convenient online submission

- Thorough peer review

- No space constraints or color figure charges

- Immediate publication on acceptance

- Inclusion in PubMed, CAS, Scopus and Google Scholar

- Research which is freely available for redistribution 